\title{
A Viral Double-Stranded RNA Up Regulates the Fungal Virulence of Nectria radicicola
}

\author{
II-Pyung Ahn and Yong-Hwan Lee \\ School of Agricultural Biotechnology and Research Center for New Bio-Materials in Agriculture, Seoul \\ National University, Suwon 441-744, Korea \\ Accepted 12 December 2000.
}

\begin{abstract}
Double-stranded RNAs (dsRNAs) are widespread in plant pathogenic fungi, but their functions in fungal hosts remain mostly unclear, with a few exceptions. We analyzed dsRNAs from Nectria radicicola, the causal fungus of ginseng root rot. Four distinct sizes of dsRNAs, 6.0, 5.0, 2.5, and $1.5 \mathrm{kbp}$, were detected in 24 out of the 81 strains tested. Curing tests of individual dsRNAs suggested that the presence of 6.0-kbp dsRNA was associated with high levels of virulence, sporulation, laccase activity, and pigmentation in this fungus. The 6.0-kbp dsRNA-cured strains completely lost virulence-related phenotypes. This 6.0-kbp dsRNA was reintroduced by hyphal anastomosis to a dsRNA-cured strain marked with hygromycin resistance, which resulted in the restoration of virulencerelated phenotypes. These results strongly suggest that 6.0kbp dsRNA up regulates fungal virulence in $N$. radicicola. Sequencing of several cDNA clones derived from 6.0-kbp dsRNA revealed the presence of a RNA-dependent RNA polymerase (RDRP) gene. Phylogenetic analysis showed that this gene is closely related to those of plant cryptic viruses. Biochemical analyses suggested that the 6.0-kbp dsRNA may regulate fungal virulence through signaltransduction pathways involving cyclic AMP-dependent protein kinase and protein kinase $\mathrm{C}$.
\end{abstract}

Additional keywords: Cylindrocarpon destructans, mycovirus, Panax ginseng.

Nectria radicicola (anamorph Cylindrocarpon destructans) is a homothallic ascomycetous fungus that causes root rots or vascular wilts on a wide variety of crops and trees worldwide (Booth 1966; Chung 1975; Matuo and Miyazawa 1969). Nectria root rot of ginseng (Panax ginseng) caused by this fungus is one of the major threats to stable ginseng production (Chung 1975; Reeleder and Brammall 1994). Because ginseng cultivation requires fertile soil that is rich in humus and continuous shade for 6 years, this disease is manifested in young and mature plants throughout ginseng-growing regions. Chemical treatments of soil have not been effective in controlling the disease, and resistant germ plasm is not yet avail-

Corresponding author: Y.-H. Lee; Telephone: +82-31-290-2446; Fax: +82 31294 5881; E-mail: yonglee @ plaza.snu.ac.kr

The sequence reported in this paper has been deposited in the GenBank database under accession no. AF251278. able (Kwon et al. 1998; Miyazawa 1966). Although a biological control strategy promoting soil suppressiveness has been applied and offered as an alternative means of controlling this disease (Chung and Kim 1978), a better understanding of the mechanisms of virulence of the pathogen is required to establish novel control strategies. Nectria root rot also is known as one of the most detrimental factors in replant failure in ginseng cultivation. It has been suggested that replant failure might be caused by the increase of a highly pathogenic population of the fungus among the soil microbial community in the field (Chung 1975; Hopkins et al. 1992; Ziezold et al. 1998). The mechanisms underlying replant failure, however, remain to be studied.

Double-stranded RNAs (dsRNAs) are widespread in all classes of plant-pathogenic fungi (Buck 1986). Although many of the dsRNAs in fungi are present as unencapsidated forms, they are believed to have originated from mycoviruses. Mycovirus infections are persistent and generally asymptomatic. In some fungi, however, dsRNA-mycovirus infection causes distinct morphological and physiological changes, including toxin production (Magliani et al. 1997; Varga et al. 1994), cytological alterations of cellular organelles (Newhouse et al. 1983), and virulence-associated traits such as growth rate (Boland 1992), sporulation (Bottacin et al. 1994), pigmentation (Anagnostakis 1979), and enzymatic activities (Rigling and Van Alfen 1993).

The Rhizoctonia spp. decline resulting from dsRNA infection has been suggested (Castanho and Butler 1978). Subsequent studies, however, showed that the mere presence of dsRNAs did not correlate with the virulence alteration of Rhizoctonia solani (Bharathan and Tavantzis 1990; Bharathan and Tavantzis 1991). Recently, Jian et al. (1997) reported that in $R$. solani, 6.4-kbp dsRNA was involved in the enhancement of fungal virulence, and this effect was nullified by the presence of 3.6-kbp dsRNA. Though the effect of dsRNA has been assessed extensively, the biological roles of dsRNAs in $R$. solani still remain unclear. Extensive studies on the biological roles of dsRNA have been conducted in Cryphonectria parasitica, the chestnut blight fungus (Anagnostakis 1979; Chen et al. 1994; Choi and Nuss 1992a; Fulbright 1984). The conversion of a virulent strain to a hypovirulent one coincided with transmission of dsRNAs by hyphal anastomosis (Anagnostakis 1979). Because dsRNAs were not introduced into fungal cells as a cell-free form that can replicate subsequently, this study did not demonstrate the direct cause-andeffect relationship to satisfy Koch's postulates. Choi and Nuss 
(1992a), however, reported that transformation of a virulent $C$. parasitica strain with a functionally infectious complementary DNA (cDNA) derived from hypovirulence-associated dsRNA conferred the hypovirulent phenotypes and resurrected cytoplasmic dsRNA through the transcription of the cDNA integrated into the host genome. Subsequent studies identified numerous fungal genes under the control of the dsRNA in this fungus. These genes include lac-1, a gene-encoding phenol oxidase laccase (Larson et al. 1992; Rigling and Van Alfen, 1991); vir-2, a gene encoding a putative hormone (Zhang et al. 1993); $c b h-1$, a gene encoding the cellobiohydrolase I CBH-1 (Wang and Nuss 1995); and cpg-1, a gene-encoding G protein alpha subunit CPG-1 (Choi et al. 1995). Chen et al. (1996) and Larson et al. (1992) reported that dsRNA also affects signal-transduction pathways of the fungus, including cyclic AMP (cAMP)- and $\mathrm{Ca}^{2+}$-dependent signaling pathways. The hypovirulence phenotype induced by the presence of dsRNA in this fungus was mimicked by the transgenic cosuppression of cpg-1 expression (Choi et al. 1995; Nuss 1996). These studies demonstrated that a better understanding of the hypovirulence mechanisms caused by the dsRNA would bring new insights into the understanding of mechanisms of fungal virulence. Such knowledge might lead to the identification of new target sites to develop novel strategies for controlling plant diseases.

In this study, we report that a $6.0-\mathrm{kbp}$ dsRNA in $N$. radicicola is responsible for up regulation of fungal virulence. An RNA-dependent RNA polymerase gene present in this dsRNA is related closely to those of plant cryptic viruses containing dsRNAs as their genome. Biochemical analyses indicated that the $6.0-\mathrm{kbp}$ dsRNA also is involved in the regulation of signal-transduction pathways of the host fungal cells.

\section{RESULTS}

\section{Incidence of dsRNAs and their potential roles in $N$. radicicola.}

Four different species of dsRNAs $(6.0,5.0,2.5$, and 1.5 kbp) were detected from $N$. radicicola and named L1, L2, M, and $\mathrm{S}$, respectively (Fig. 1A). The dsRNA nature of these molecules was confirmed through cellulose (CF-11) column chromatography, with $16 \%$ ethanol concentration, and by digestion with RNase A (Boland 1992). All four dsRNAs were resistant and susceptible to $\mathrm{RNase} \mathrm{A}$ at high $(0.3 \mathrm{M} \mathrm{NaCl})$ and low $(15 \mathrm{mM} \mathrm{NaCl})$ salt concentrations, respectively. Twentyfour out of the 81 strains screened contained at least one molecule of dsRNA, indicating that the infection rate was approximately $30 \%$. The 24 strains were classified into eight groups on the basis of the dsRNA banding patterns. No strain contained all four species of dsRNAs (Fig. 1B).

To determine the biological roles of dsRNAs in this fungus, we first compared virulence, color intensity on the Bavendamm medium, and mycelial growth between dsRNAcontaining and dsRNA-free strains. There were significant differences in the level of virulence and color intensity on the Bavendamm medium, although no significant difference was detected in their mycelial growth rates (Table 1). These data raised the possibility that the presence of dsRNAs in $N$. radicicola might be involved in fungal virulence. We tested this possibility further by comparing virulence and color intensity on the Bavendamm medium of the strains with the

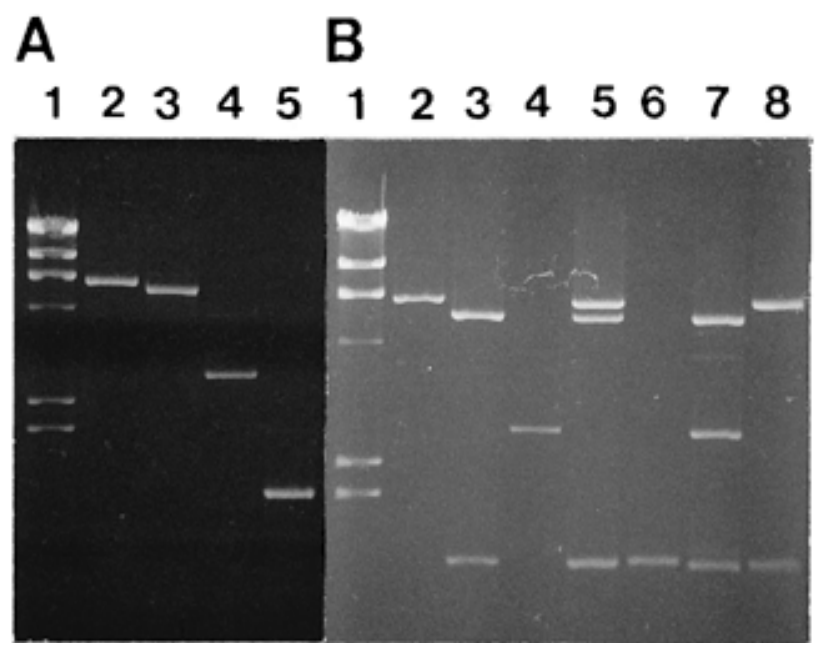

Fig. 1. Agarose gel electrophoretic analysis of dsRNAs from Nectria radicicola. A, DsRNAs were extracted from four strains containing single dsRNA molecule. Lane 1, $\lambda$ DNA digested with HindIII; lane 2, 6.0-kbp (L1) dsRNA in Cy9201; lane 3, 5.0-kbp (L2) dsRNA in JP3-2-2; lane 4, 2.5-kbp (M) dsRNA in SW3-5-3; and lane 5, 1.5-kbp (S) dsRNA in TSW3-4-1. B, DsRNAs were extracted from strains containing dsRNA(s) singly or in combination. Lane $1, \lambda$ DNA digested with HindIII; lane 2, Cy9201; lane 3, JP3-2-2; lane 4, SW3-5-3; lane 5, TSW3-4-1; lane 6, TSW3-4-1; lane 7, TJP3-5-2; and lane 8, TJP3-5-1.

Table 1. Contrasts between means of dsRNA-containing and dsRNA-free strains of Nectria radicicola

\begin{tabular}{|c|c|c|c|c|c|}
\hline Variables & $\operatorname{dsRNA}(s)^{\mathbf{a}}$ & Mean \pm SD with dsRNAs & Mean \pm SD without dsRNAs & $F$ with dsRNA & $P>F^{b}$ without dsRNA \\
\hline \multirow{2}{*}{ Virulence $^{c}$} & Total (24) & $1.48 \pm 0.63$ & $1.20 \pm 0.65$ & 7.50 & 0.0076 \\
\hline & L1 (14) & $1.62 \pm 0.48$ & $1.10 \pm 0.65$ & 9.42 & 0.0029 \\
\hline \multirow[t]{2}{*}{ Bavendamm reaction $^{\mathrm{d}}$} & Total (24) & $1.45 \pm 0.62$ & $1.11 \pm 0.62$ & 14.09 & 0.0003 \\
\hline & L1 (14) & $1.40 \pm 0.68$ & $1.04 \pm 0.64$ & 7.13 & 0.0092 \\
\hline \multirow{2}{*}{ Growth rate $e^{e}$} & Total (24) & $2.52 \pm 0.18$ & $2.48 \pm 0.19$ & 0.86 & 0.1765 \\
\hline & L1 (14) & $2.47 \pm 0.15$ & $2.48 \pm 0.20$ & 0.54 & 0.4652 \\
\hline
\end{tabular}

a Total denotes the group of $N$. radicicola strains that contained at least one molecule of dsRNAs. L1 is the group of strains that harbored L1 dsRNA, regardless of the presence of the other three dsRNAs. Numbers in parentheses indicate number of isolates.

${ }^{\mathrm{b}}$ Probability of obtaining a larger absolute value of $F$ is $(P=0.05)$.

${ }^{c}$ Virulence represents the mean disease severity value. Disease severity was assessed with a scale of $0-2$, where $0=$ no disease; $1=$ root rot symptoms exhibiting a whitish brown and small symptom diameter of less than $5 \mathrm{~mm}$; and $2=$ severe root rots exhibiting a deep brown and large symptom diameter of more than $5 \mathrm{~mm}$.

d Bavendamm reaction was determined by color reaction on Bavendamm's medium with a scale of $0-2$, where $0=$ no growth and/or pigmentation; $1=\mathrm{a}$ faint brown; and 2 = a deep-brown or reddish-brown.

${ }^{\mathrm{e}}$ Growth rate was measured as the colony diameter on Czapek Dox agar at $20^{\circ} \mathrm{C}$ for 7 days in the dark. 
presence and absence of individual dsRNAs. The mean values of virulence and color intensity on the Bavendamm medium of the strains containing L1 dsRNA were significantly different from those of the strains lacking L1 dsRNA (Table 1). The presence of the remaining three (L2, M, and S), however, did not significantly affect the virulence and color intensity on the Bavendamm medium, which strongly suggests that L1 dsRNA in $N$. radicicola might be responsible for the increased level of fungal virulence.

Previous studies suggested that replant failure in ginseng cultivation is, in part, a result of the increase of a highly pathogenic population of fungus in the soil microbial community during prolonged cultivation in the same field (Chung 1975). Considering the strong correlation between the presence of L1 dsRNA and the higher virulence, we hypothesized that the size of the L1 dsRNA-containing population increases during prolonged cultivation. We surveyed strains isolated from different geographic areas and different time lengths of ginseng cultivation for the presence of L1 dsRNA. Table 2

Table 2. Comparison of virulence and Bavendamm reaction and the presence of L1 dsRNA between the Nectria radicicola strains recovered from the first cropping and the replanted fields

\begin{tabular}{|c|c|c|c|c|}
\hline \multirow[b]{2}{*}{ Variables } & \multicolumn{2}{|c|}{ Kyonggi } & \multicolumn{2}{|c|}{ Chungbuk } \\
\hline & First & Replanted & First & Replanted \\
\hline o. of isolate & 1 & & 27 & 6 \\
\hline $\begin{array}{l}\text { containing } \\
\text { isolates }\end{array}$ & 6 & & 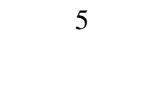 & 6 \\
\hline $\begin{array}{l}\text { No. of L1 dsRNA } \\
\text { containing } \\
\text { isolates }\end{array}$ & 2 & 7 & 1 & 4 \\
\hline Virulen & $\pm 0.6 y$ & $4 \pm 0.3 z$ & \pm 0. & $.3 \pm$ \\
\hline $\begin{array}{l}\text { Bavendamm } \\
\text { reaction }^{\mathrm{b}}\end{array}$ & $\pm 0.8 \mathrm{z}$ & & & \\
\hline \multicolumn{5}{|c|}{$\begin{array}{l}\text { a Virulence represents the mean disease severity value. Disease severity } \\
\text { was assessed with a scale of } 0-2 \text {, where } 0=\text { no disease; } 1=\text { root rot } \\
\text { symptoms exhibiting a whitish brown and small symptom diameter of } \\
\text { less than } 5 \mathrm{~mm} \text {; and } 2=\text { severe root rots exhibiting a deep-brown and } \\
\text { large symptom diameter of more than } 5 \mathrm{~mm} \text {. Means followed by the } \\
\text { same letter within the same geographic origin are not significantly } \\
\text { different, per Duncan's multiple range tests }(P=0.05) \text {. } \\
\text { b Bavendamm reaction was determined by color reaction on Baven- } \\
\text { damm's medium with scale of } 0-2 \text {, where } 0=\text { no growth and/or pig- } \\
\text { mentation; } 1=\text { faint brown; and } 2=\text { deep-brown or reddish brown. }\end{array}$} \\
\hline
\end{tabular}

shows the detection frequencies of dsRNAs from different sources. Thirteen out of the 38 strains (34\%) from the Korean province Kyonggi contained at least one dsRNA molecule, and the infection rate among strains collected in the Korean province Chungbuk was about 26\% (11 out of the 43 isolates). Among the strains collected from the first cropping ginseng fields, dsRNA infection rates were 28 and $18 \%$ in the strains from Kyonggi and Chungbuk, respectively. In the strains collected from the replanted fields, however, dsRNA infection rates were $41 \%$ in Kyonggi and $38 \%$ in Chungbuk. All four dsRNA molecules were detected, regardless of the field history in either province. In the first cropping fields, the infection rates of L1 dsRNA were $9 \%$ in Kyonggi and $4 \%$ in Chungbuk. In the replanted fields, however, the infection rates of L1 dsRNA increased abruptly to $41 \%$ in Kyonggi and $25 \%$ in Chungbuk. Virulence and color intensity on the Bavendamm medium of the fungal strains from replanted fields in both provinces also were increased. These data suggest that a higher frequency of $N$. radicicola strains harboring L1 dsRNA in replanted ginseng fields may be correlated to the increase of more pathogenic isolates in the soil.

\section{Elimination of L1 dsRNAs significantly reduced virulence-related traits.}

To understand the physiological role of individual dsRNA molecules, we attempted to cure specific dsRNAs from representative strains harboring a single species of dsRNA molecule. The representative strains used in this study were Cy9201 for L1, JP3-2-2 (JP) for L2, SW3-5-3 (SW) for M, and TSW3-4-1 (TSW) for S dsRNA (Fig. 1A). These strains were virulent on ginseng roots, produced strong color reaction on the Bavendamm medium, exhibited normal colony morphology, and had a high degree of sporulation ability (Table 3). After over 3,000 trials to obtain dsRNA-cured strains with cycloheximide and/or emetine (Fulbright 1984), dsRNA-cured strains were recovered from each representative strain: Cy9201W from Cy9201, JPC from JP, SWC from SW, and TSWC from TSW. Comparisons of the wild type strains containing L2, M, or S dsRNA with those of the corresponding dsRNA-cured strains did not reveal detectable differences in virulence, color intensity on the Bavendamm medium, colony morphology, and sporulation ability (Table 3). These data suggest that L2, M, and S dsRNAs had little effect, if any, on

Table 3. Effects of eliminating dsRNAs of Nectria radicicola on fungal characteristics

\begin{tabular}{|c|c|c|c|c|c|c|c|c|c|}
\hline & \multicolumn{3}{|c|}{ L1 } & \multicolumn{2}{|c|}{ L2 } & \multicolumn{2}{|c|}{ M } & \multicolumn{2}{|c|}{$\mathbf{S}$} \\
\hline & Су9201 & Cy9201W & NcCy9201 & $\mathbf{J P}$ & JPC & SW & SWC & TSW & TSWC \\
\hline DsRNAs & + & - & - & + & - & + & - & + & - \\
\hline Mycelial growth $(\mathrm{cm})^{\mathrm{a}}$ & $2.9 \pm 0.3$ & $6.2 \pm 0.4$ & $5.9 \pm 0.1$ & $3.2 \pm 0.2$ & $3.5 \pm 0.3$ & $3.2 \pm 0.3$ & $3.0 \pm 0.1$ & $2.9 \pm 0.3$ & $3.0 \pm 0.4$ \\
\hline Sporulation $\left(\times 10^{6} / \mathrm{ml}\right)^{\mathrm{b}}$ & $4.8 \pm 1.4$ & 0 & 0 & $6.3 \pm 1.8$ & $2.7 \pm 0.4$ & $3.3 \pm 1.3$ & $3.4 \pm 0.9$ & $2.8 \pm 1.2$ & $3.7 \pm 0.9$ \\
\hline Virulence $^{c}$ & 1.7 & 0 & 0 & 2.0 & 2.0 & 2.0 & 2.0 & 2.0 & 2.0 \\
\hline Bavendamm reaction $^{\mathrm{d}}$ & 2.0 & 0 & 0 & 2.0 & 2.0 & 2.0 & 2.0 & 2.0 & 2.0 \\
\hline
\end{tabular}

${ }^{a}$ Mycelial growth was measured as the diameter of colony at 7 days after incubation on Czapek Dox agar in the dark at $20^{\circ} \mathrm{C}$.

${ }^{\mathrm{b}}$ Sporulation was examined in $5 \mathrm{ml}$ of V8 juice broth at 8 days after incubation with $1 \times 1 \mathrm{~mm}^{2}$ Czapek Dox agar block. The cultures were incubated at $20^{\circ} \mathrm{C}$ with shaking at $120 \mathrm{rpm}$ in the dark.

${ }^{c}$ Virulence represents the mean disease severity value. Disease severity was assessed with a scale of $0-2$, where $0=$ no disease; $1=$ root rot symptoms exhibiting a faint brown and a small symptom diameter of less than $5 \mathrm{~mm}$; and $2=$ severe root rots exhibiting a deep brown and a large symptom diameter of more than $5 \mathrm{~mm}$.

${ }^{\mathrm{d}}$ Bavendamm reaction was determined by color reaction on Bavendamm's medium with a scale of $0-2$, where $0=$ no growth and/or pigmentation; $1=\mathrm{a}$ faint brown; and 2 = a deep brown. Strain Cy9201 contained L1, 6.0-kbp dsRNA, and Cy9201W was the subculture of Cy9201 that eliminated L1 dsRNA with cycloheximide treatment. NcCy9201 was the dsRNA-free Cy9201 strain recovered through conidiogenesis. The relationships between JP and JPC, SW and SWC, and TSW and TSWC are identical to that of Cy9201 and Cy9201W. 
fungal physiology. In contrast, there were significant differences in virulence and virulence-related phenotypes, including laccase activities and asexual sporulation between Cy9201 and Cy9201W. NcCy9201, another L1 dsRNA-cured strain of

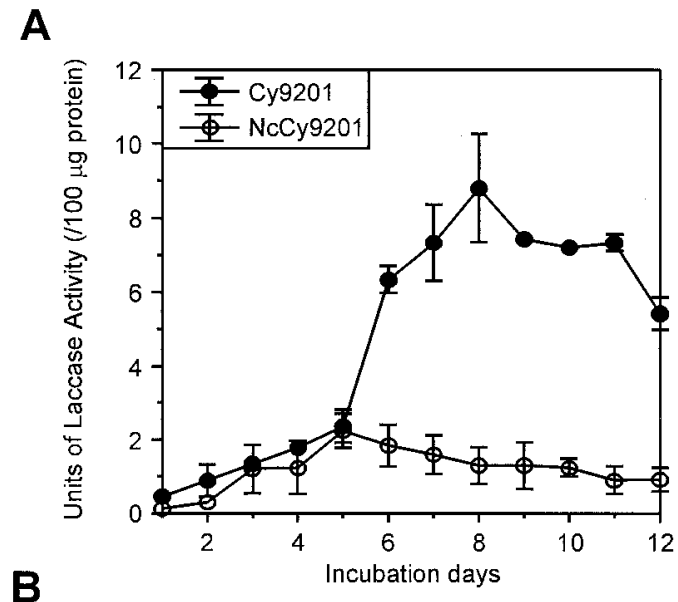

B

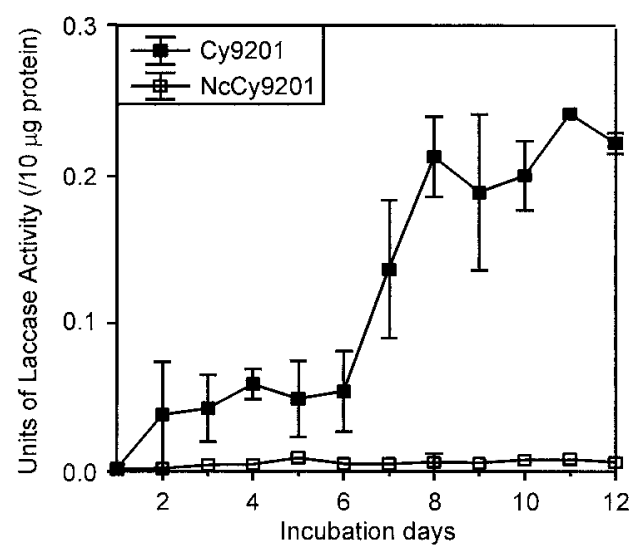

C

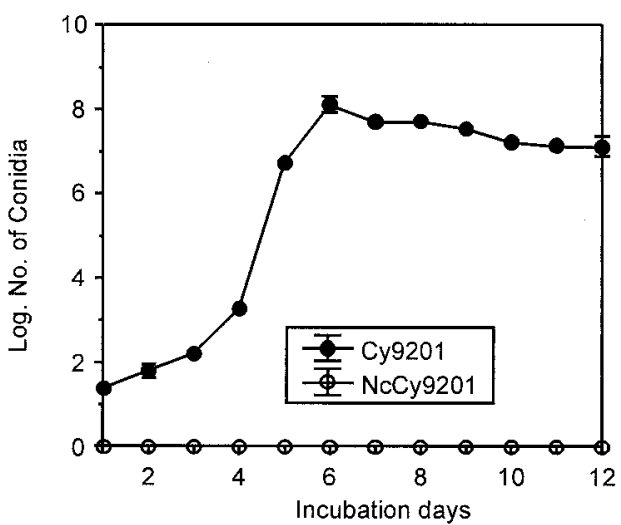

Fig. 2. Comparison of laccase activities and sporulation abilities in Cy9201 and NcCy9201. Proteins from mycelia and culture filtrates were used for measuring intracellular and extracellular laccase activities, respectively. Laccase activity was determined with 2,6-dimethoxyphenol as the substrate. One unit was defined as an increase of absorbance of 1.0 per min at $468 \mathrm{~nm}$ and at $25^{\circ} \mathrm{C}$. All measurements were conducted with three replications. A, Intracellular laccase activities; $100 \mu \mathrm{g}$ of total protein was used for each analysis. B, Extracellular laccase activities; 10 $\mu \mathrm{g}$ of total protein was used for each analysis. C, Sporulation was examined in $5 \mathrm{ml}$ of $\mathrm{V} 8$ juice broth at 8 days after inoculation with approximately 1,000 conidia.
Cy9201 obtained through asexual sporulation followed by single-spore isolation, also exhibited a similar phenotype (Table 3). Strains $\mathrm{Cy} 9201 \mathrm{~W}$ and $\mathrm{NcCy} 9201$ failed to produce any root-rot symptoms in pathogenicity tests and showed white colony color, which is different from the wild type. Time-course experiments also were conducted to determine the effect of L1 dsRNA on laccase activity. Strain Cy9201 exhibited strong intracellular and extracellular laccase activities, which peaked at 8 days postincubation in Czapek Dox broth. Only residual enzymatic activities were detected, however, during an incubation period of up to 12 days in the L1 dsRNA-cured strain NcCy9201. Furthermore, this strain completely lost its sporulation ability, whereas Cy9201 sporulated profusely in culture (Fig. 2 and Table 4). These results further support that L1 dsRNA in strain Cy9201 is responsible for up regulating virulence and virulence-associated traits.

\section{Acquisition of L1 dsRNA restored fungal virulence.}

To prove this hypothesis, we reintroduced L1 dsRNA into a cured strain, NcCy9201. Because it is not possible to introduce dsRNA molecules as a cell-free form directly into fungal cells, we used hyphal anastomosis toward this goal. To clearly differentiate Cy9201, a donor strain from NcCy9201, we marked NcCy9201, a recipient strain, with antibiotic resistance by transforming it with a bacterial hygromycin B resistance gene $(H P H)$. We tested the hygromycin B sensitivity of NcCy9201 on Fusarium minimal medium (FMM) supplemented with 20 or $50 \mathrm{ppm}$ of hygromycin B. Mycelia of $\mathrm{NcCy} 9201$ did not grow in either antibiotic concentrations

Table 4. Comparison of mycelial growth, sporulation, laccase activities, and virulence among L1 dsRNA-containing Cy90201, L1 dsRNA-free NcCy9201, and L1 dsRNA-reintroduced T-1(3) of Nectria radicicola

\begin{tabular}{lccc}
\hline Variables & Cy9201 & NcCy9201 & T-1(3) \\
\hline L1 dsRNA & + & - & + \\
Colony color $^{\mathrm{a}}$ & Brown & White & Brown \\
${\text { Mycelial growth }(\mathrm{cm})^{\mathrm{b}}}^{\mathrm{b}}$ & $2.9 \pm 0.3$ & $5.90 \pm 0.1$ & $2.9 \pm 0.2$ \\
${\text { Sporulation }\left(\times 10^{6} / \mathrm{ml}^{\mathrm{c}}\right.}^{\mathrm{c}}$ & $4.8 \pm 1.4$ & 0.0 & $2.7 \pm 0.6$ \\
Bavendamm reaction $^{\mathrm{d}}$ & Strong & No growth & Strong \\
Laccase activity $^{\mathrm{e}}$ & & & \\
$\quad$ Intracellular & $9.6 \pm 2.7$ & $1.10 \pm 0.3$ & $8.8 \pm 2.4$ \\
$\quad$ Extracellular & $0.4 \pm 0.1$ & $0.02 \pm 0.01$ & $0.6 \pm 0.3$ \\
Disease incidence $(\%)^{\mathrm{f}}$ & $3 / 4$ & $0 / 4$ & $3 / 4$ \\
${\text { Virulence }(\mathrm{mm} 2)^{\mathrm{g}}}$ & $96.3 \pm 12.7$ & 0.0 & $59.6 \pm 22.1$ \\
\hline
\end{tabular}

${ }^{\text {a }}$ Colony color was determined at 8 days post incubation on Czapek Dox agar at $20^{\circ} \mathrm{C}$ in the dark.

${ }^{\mathrm{b}}$ Mycelial growth was estimated by measuring the diameter of colony on Czapek Dox agar at 8 days after incubation at $20^{\circ} \mathrm{C}$ in the dark.

${ }^{\mathrm{c}}$ Sporulation was estimated in V8 juice broth at 8 days after inoculation with $1 \times 1 \mathrm{~mm}^{2}$ Czapek Dox mycelial block. The cultures were incubated at $20^{\circ} \mathrm{C}, 120 \mathrm{rpm}$ in the dark.

d Bavendamm reaction was determined by color reaction on Bavendamm's medium with a scale of $0-2$, where 0 represents no growth and/or pigmentation; 1 = faint brown; and 2 = deep brown or reddish brown

${ }^{\mathrm{e}}$ Laccase activity of cultures grown in Czapek Dox broth at 8 days after inoculation. One laccase unit was defined as an increase in the liter of $\Delta \mathrm{A}_{468}$ per min at $25^{\circ} \mathrm{C}$. In the intracellular laccase assay, $100 \mu \mathrm{g}$ of total protein was used. Extracellular laccase assay was performed with $10 \mu \mathrm{g}$ of total protein.

${ }^{f}$ Disease incidence was assessed on dormant, 2-year-old ginseng plants. Four ginseng seedlings were planted in each pot containing $N$. radicicola-infested soil (inoculum grown on rye grain-soil $=0.1 \mathrm{~g}-1 \mathrm{~kg}$ ). Disease incidence was then estimated at 2 weeks after planting.

${ }^{g}$ Virulence was represented as the mean of Nectria root rot area on all four plants in each treatment. 
with prolonged incubation up to 4 weeks. All transformants containing the $H P H$ gene, however, grew on the medium supplemented with $50 \mathrm{ppm}$ of hygromycin B. The hygromycin resistance of the transformants was very stable during serial transfers on hygromycin-free media. Southern blot hybridization analysis verified that the $H P H$ gene had been integrated into the genome of $\mathrm{NcCy} 9201$ (data not shown). These transformants did not exhibit any significant physiological differences, including cultural morphology, colony color, virulence, sporulation, and Bavendamm reaction (except for resistance to hygromycin B), in comparison to $\mathrm{NcCy} 9201$. These data suggested that the transformants could be used as recipients without altering the genetic and physiological characteristics of NcCy9201.

Transmission of L1dsRNA from $\mathrm{Cy} 9201$ to a recipient strain (T-1, a transformant of NcCy9201 with $H P H$ ) was achieved by hyphal anastomosis. To identify that T-1 had acquired L1 dsRNA, two selection schemes were employed. First, hygromycin B was used to discriminate the recipient strain. Second, changing colony color on the Bavendamm medium was used to select the L1 dsRNA acquisition. Strain Cy9201 produces a strong color reaction on the Bavendamm medium, but NcCy9201 did not produce any color reaction. T-
1 strains that acquired L1 dsRNA were expected to produce a strong color reaction on the Bavendamm medium. Mycelial plugs were taken from the opposite side of recipient colony margins at 4 days after the two strains contacted each other. Two strains, T-1(1) and T-1(3), among 132 explants, produced a strong color reaction on the Bavendamm medium and exhibited hygromycin B resistance, suggesting the presence of L1 dsRNA. A Northern analysis confirmed the presence of L1 dsRNA in T-1(3) strain (data not shown). The presence of $H P H$ in these strains was also confirmed by Southern analysis (data not shown).

Acquisition of L1 dsRNA by T-1-restored sporulation ability, color intensity on the Bavendamm medium, intracellular and extracellular laccase activities, and cultural morphology of T-1 to those of Cy9201, a strain containing L1 dsRNA as shown in Table 4. Furthermore, virulence of T-1(3) also was increased significantly. Infection assays with Cy9201, NcCy9201, and T-1(3), under in vitro and in vivo conditions, indicated that fungal virulence was restored by the acquisition of L1 dsRNA in T-1(3) strain (Fig. 3 and Table 4). This series of experiments demonstrated that L1 dsRNA is responsible for the up regulation of virulence in $N$. radicicola strain Cy9201 by satisfying Koch's postulates. The fact that some strains
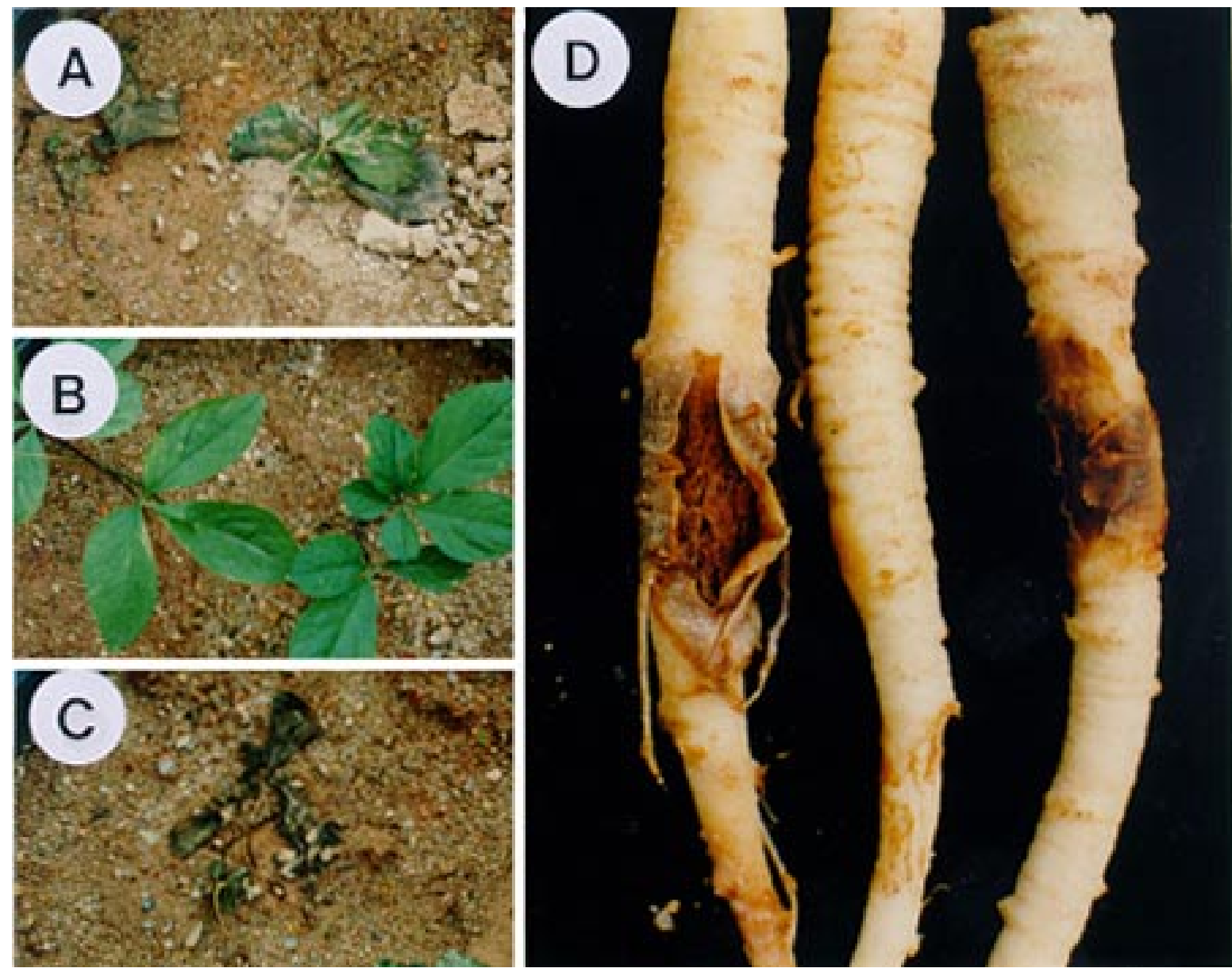

Fig. 3. Pathogenicity assays of Nectria radicicola on 2-year-old ginseng. Each pot was infested with rye grain inoculum $(0.1 \mathrm{~g}$ per $\mathrm{kg}$ of soil) of fungal strains and ginseng was planted in pots containing infested soil. Disease ratings and photographing was performed at 2 weeks postplanting. A, Aboveground parts of ginseng planted in Cy9201-infested soil. B, Above-ground parts of ginseng planted in NcCy9201-infested soil. C, Above-ground parts of ginseng planted in T-1(3)-infested soil. D, Nectria root rot symptoms on ginseng roots inoculated with Cy9201, NcCy9201, and T-1(3) (from left to right). 
lacking L1 dsRNA also showed strong virulence suggests that L1 dsRNA in this fungus may not function in all strains in the same manner.

\section{Molecular characterization of L1 dsRNA.}

To determine the molecular nature of L1 dsRNA, we constructed a cDNA library from this molecule. The size of the cDNA insert ranged from $300 \mathrm{bp}$ to $1.1 \mathrm{kbp}$. Sequencing of several overlapping cDNA clones, including pL1-11 $(1,105$ bp), pL1-29 (825 bp), pL1-59 (856 bp), and pL1-72 (751 bp), produced 1,287 bp of continuous nucleotide sequence of L1 dsRNA (GenBank accession no. AF251278). A BLAST search (Altschul et al. 1988) with this sequence revealed that L1 dsRNA contains an RNA-dependent RNA polymerase (RDRP) gene. Although the available sequence of L1 dsRNA does not cover the full open reading frame for the RDRP gene, this sequence contains three conserved regions of RDRP identified by Poch et al. (1989). Alignments and phylogenetic analyses of these conserved regions with RDRPs from other fungal and plant viruses revealed a close evolutionary relationship with FusoVM1, a dsRNA fungal virus of Fusarium solani f. sp. robiniae (Nogawa et al. 1996). These two fungal viruses were grouped together with plant cryptic viruses, including Carrot temperate virus and Radish yellow edge virus,

A

A

$\begin{array}{lrl}\text { FusoVM1 } & (259) & \text { LDFSSF- DTKV } \\ \text { HV190SV } & (363) & \text { KDRAIFACDT-- } \\ \text { CHV1 } & (1911) & \text { ADATAY- DSNC } \\ \text { PVY } & (248) & \text { ADGSQF- DSSI } \\ \text { RsM2-1A1 } & (403) & \text { YDLTAAT-DRLP } \\ \text { CpMV1-NB631 } & (376) & \text { FDLTAAT-DRLP } \\ \text { OnuMV3 } & (320) & \text { QDGLLH- DVEF } \\ \text { BaYMV } & (273) & \text { GDGSRF- DSSI } \\ \text { ScVW } & (367) & \text { SDMKSAS-D-LI } \\ \text { BCV3 } & (261) & \text { LDWSSF--DSSV } \\ \text { RYEV } & --- & \text { LDWSEF- DMRV } \\ \text { CTeV } & --- & \text { LDWSRE- DKRA } \\ \text { NrVL1* } & --- & \text { LDWSSF- DTKV } \\ & & *\end{array}$

B

(62) GVPSGSWWTQLVDSVVNWILVKYLSLCQG

(96) TLMSGHRATTFTNSVLNAAYICYAVGIPA

(179) KNRSGGTGQSATSWDNTATFKLGVISAWA

(49) GNNSGQPSTVVDNSLMVVLAMHYALIKEC

(52) GQPMGALSSWPGLALTHHWIVQVAAFRVT

(20) GQPMGAYSSFAMLALTHHVIVQVAALNSG

(53) GQPMGALSSWAMLALSHHVIVQIAAMRVG

(48) GNNSGQPSTVVDNTLVLMTAFLYAYIHKT

(47) GILMGLPTTWAILNLMHLWCWDSADRQYR

(51) GIPSGSYYTSIVGSVVNRLRIEYIWRVLF

(57) GMPSGIFCTQFWDSFYMCIMVVTTLEALG

(71) GIPSGLFITQLLHSWYNYTMLATILSALG

(64) GVPSGSWWTQLVDSVVNWVIVEYLSLCQG
C

(5) LRVLGDDSAF

(3) SLHAGDDVYI

(12) LYNTSDDTVV

(11) FEVNGDDLLI

(8) YEILGDDIVI

(7) YCILGDDIVI

(6) YALLGDDIVI

(13) FVCNGDDNKF

(13) CRVCGDDLIG

(6) CYTQGDDSLI

(8) LKVLGDDVIF

(7) IKVQGDDSII

(3) CATQGDDYSL

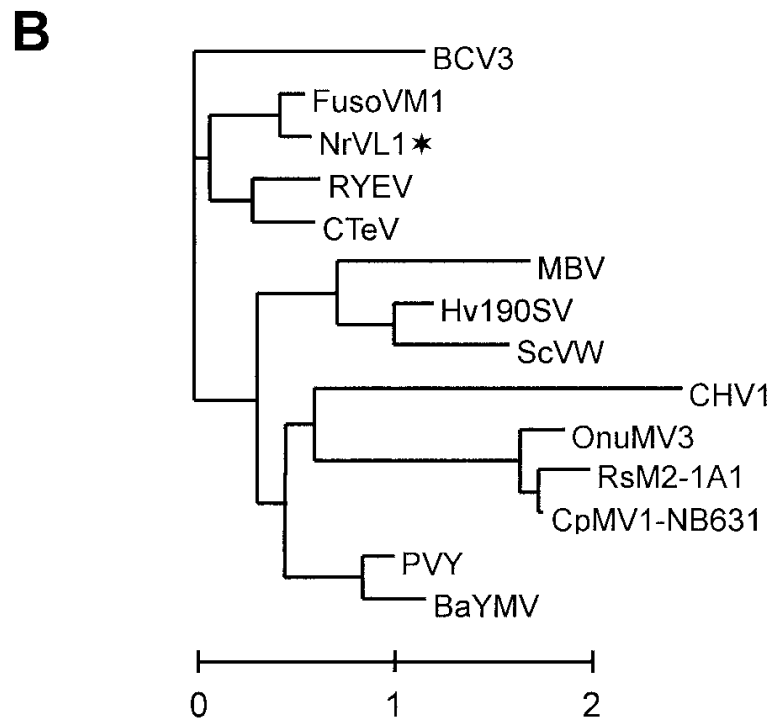

Fig. 4. Comparison of amino acids and phylogenetic relationship of RNA-dependent RNA polymerase domains of L1 dsRNA in Nectria radicicola and other fungal and plant viruses. A, Alignments were performed with the Clustal W program (Thompson et al. 1994). Sequences came from, in this work, Potato virus Y (PVY), Barley yellow mosaic virus (BaYMV), Cryphonectria parasitica Hypovirus 1 (CHV1), Mushroom bacilliform virus (MBV) (Revill et al. 1994), Helminthosporium victoriae $190 \mathrm{~S}$ viral dsRNA (Hv190SV), Rhizoctonia solani 3.6-kbp M2 dsRNA (RsM2-1A1) (Strauss et al. 2000), Ophiostoma novo-ulmi 3a dsRNA (OnuMV3) (Hong et al. 1999), mitochondrial dsRNA of C. parasitica strain NB631 (CpMV1-NB631); Saccharomyces cerevisiae W dsRNA (ScVW); and Nectria radicicola $\mathrm{L} 1$ dsRNA (NrVL1). Sequences also came from Fusarium solani f. sp. robiniae dsRNA (FusoVM1), Carrot temperate virus (CTeV), and Radish yellow edge virus (RYEV). Asterisk indicates identical amino acids residues; colon indicates chemically similar residues. Numbers in parentheses are numbers of amino acid residues between regions. B, Parsimonious tree was drawn with the TreeView program (Page 1996). Branch lengths are proportional to the distances calculated. A logarithmic scale showing this distance is at the bottom. 
whereas the remaining fungal viruses were grouped together with plant single-stranded RNA viruses (Fig. 4).

To determine sequence similarity among the four different dsRNAs in this fungus, Northern hybridization was performed with a probe, pL1-72, that contains part of the RDRP gene encoded by L1 dsRNA. This probe hybridized strongly to L2 and S dsRNAs, indicating a high degree of sequence homology among L1, L2, and S dsRNAs. No hybridization signal was detected, however, with M dsRNA (Fig. 5A). The probe also hybridized strongly to the $6.0-\mathrm{kbp}$ dsRNAs present in all 11 strains of $N$. radicicola (Fig. 5B).

DsRNAs in fungi are generally believed to be the genome of fungal viruses. We attempted to purify virus particles from five strains that contain L1 dsRNA. All efforts to purify virus particles failed. No typical virus particles were observed in various viral preparations (data not shown), and pL1-72 hybridized to dsRNAs in viral preparations of the five strains (Fig. 5C).

\section{Protein kinase assays.}

As an initial step to dissect the biochemical mechanisms involved in hypervirulence as a result of the presence of L1 dsRNA in this fungus, we measured the activities of two protein kinases involved in fungal pathogenicity (Larson et al. 1992; Lee and Dean 1993; Lee and Lee 1998). Activities of cAMP- and $\mathrm{Ca}^{2+}$-dependent protein kinases (PKA and PKC respectively) were measured in $\mathrm{Cy} 9201, \mathrm{NcCy} 9201$, and T1(3). The activities of PKA and PKC were oppositely regulated by the presence of L1 dsRNA (Fig. 6). PKA activities of Cy9201 and T-1(3) were $9.4 \pm 1.3$ and $9.1 \pm 0.9$ pmole per 5 $\mu \mathrm{g}$ of total protein per min, respectively, whereas that of NcCy9201 was $1.6 \pm 1.1$, suggesting that L1 dsRNA stimulated PKA activity. PKC activities of Cy9201 and T-1(3), however, were $1.6 \pm 0.5$ and $1.5 \pm 1.1$ pmole per $10 \mu \mathrm{g}$ of total protein per min, respectively, whereas that of NcCy9201 was $4.7 \pm 0.9$.

\section{DISCUSSION}

A considerable amount of studies has been conducted to elucidate the function of dsRNAs in plant-pathogenic fungi (Hollings 1982), but their functions still remain elusive, with the exception of the hypovirulence phenomenon in $C$. parasitica (Kazmierczak et al. 1996; Nuss 1996; Zhang et al. 1993). Although the hypovirulent phenotype associated with the presence of dsRNAs has been reported in several other fungi, most of these studies were limited, demonstrating statistical correlation only between the presence of dsRNAs and altered virulence (Bharathan and Tavantzis 1990; Bharathan and Tavantzis 1991; Kousik et al. 1994; Tooley et al. 1989). We report here that a dsRNA in $N$. radicicola significantly affects virulence and other traits.

\section{Characterization of dsRNAs in $N$. radicicola.}

Approximately $30 \%$ of $N$. radicicola strains surveyed (24 out of 81) were infected by at least one of the dsRNAs. This infection rate was compatible to those of other plant pathogenic fungi (Hollings 1982). Complete infection by dsRNAs also was reported in all 51 stains of $R$. solani collected from diverse geographic origins (Bharathan and Tavantzis 1990; Bharathan and Tavantzis 1991). The molecular sizes of dsRNAs in $N$. radicicola, ranging from 1.5 to $6.0 \mathrm{kbp}$, also are similar to those in other fungal pathogens (Boland 1992; Chun and Lee 1997; Elias and Cotty 1996; Hammar et al. 1989; McFadden et al. 1983; Varga et al. 1994), with the exception of $R$. solani, which carries large 23 to $25 \mathrm{kbp}$ dsRNAs (Bharathan and Tavantzis 1990; Bharathan and Tavantzis 1991; Kim et al. 1996).

The number and size of dsRNAs in fungi are very diverse and highly variable, depending upon the fungal species (Elias and Cotty 1996; Rogers et al. 1986; Varga et al. 1994). The presence of multispecies of dsRNA in a single strain is proba-

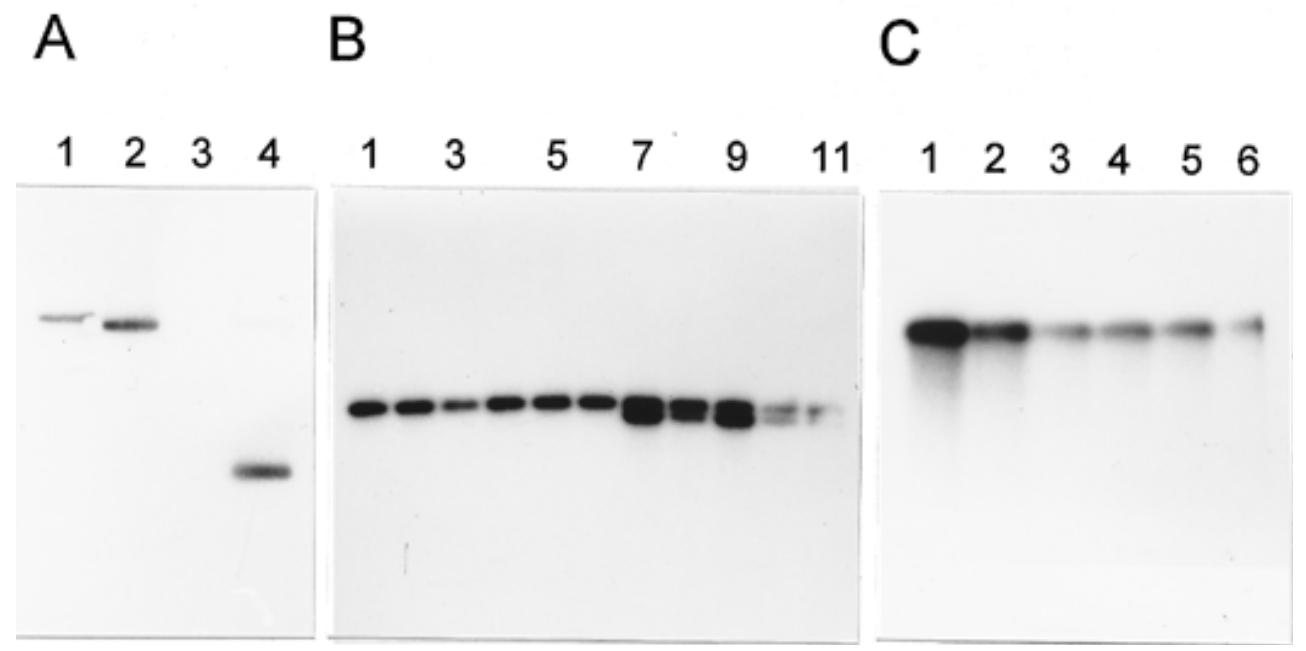

Fig. 5. Northern blot hybridization analyses of dsRNAs in Nectria radicicola. A, Sequence homology among four species of dsRNAs. Lane 1 , L1 dsRNA in Cy9201; lane 2, L2 dsRNA in JP3-2-2 (JP); lane 3, M dsRNA in SW3-5-3 (SW); lane 4, S dsRNA in TSW3-4-1 (TSW). The blot was hybridized with radiolabeled pL1-72, a cDNA clone of L1 dsRNA in Cy9201. B, Sequence homology among 6.0-kbp dsRNAs in 11 isolates of N. radicicola. Lane 1, Cy9201; lane 2, Cy9404; lane 3, SW3-1-1; lane 4, SW3-9-9; lane 5, TSW3-3-1; lane 6, TJP3-5-1; lane 7, SW3-4-3; lane 8, TSW3-3-3; lane 9, TJP3-4-1; lane 10, Cy9402, lane 11, Cy9406. The blot was hybridized with radiolabeled pL1-72, a cDNA clone of L1 dsRNA in Cy9201. Doublets in lanes 7-11 were the result of the presence of L1 and L2 dsRNAs. C, Northern blot hybridization analysis of dsRNAs in partially purified viral samples from four strains of $N$. radicicola. All five strains harbored a single, 6.0-kbp dsRNA. Lane 1, Cy9201; lane 2, viral preparation from Cy9201; lane 3, viral preparation from Cy9404; lane 4, viral preparation from SW3-1-1; lane 5, viral preparation from SW3-9-9; lane 6, viral preparation from TSW3-31. The blot was hybridized with radiolabeled pL1-72, a cDNA clone of L1 dsRNA in Cy9201. 
bly caused by multiple infection by more than one type of virus or the frequent generation of deletion products from a large dsRNA molecule. Polymorphisms of dsRNAs in $N$. radicicola were relatively simple, resulting mainly from the small number of dsRNA detected (four) and a high frequency of strains harboring a single dsRNA (nine out of 24 strains). Up to three types of dsRNAs were detected in a strain of this fungus. Interestingly, $M$ dsRNA was not detected with L1 dsRNA, suggesting that $\mathrm{M}$ and L1 dsRNAs were either mutually exclusive or derived from different ancestral viruses requiring two independent infection events. The lack of sequence homology between L1 and M dsRNAs supports the later possibility. Our marked strain, T-1, could be used to test the former possibility. Although L1 dsRNA hybridized to L2 and S dsRNAs, it remains to be determined whether L2 and S dsRNAs are deletion products of L1 dsRNA. Sequence comparison of these three molecules will answer this question.

The origin of dsRNAs in plant-pathogenic fungi appears quite complex. DsRNAs of the same size and even derived from strains collected within a single field or county might not share common nucleotide sequences (Chung et al. 1994; Lakshman and Tavantzis 1994). L1 dsRNA of strain Cy9201 hybridized to all $6.0-\mathrm{kbp}$ dsRNAs present in 11 strains that were isolated from several different sources in two geographic regions. These data indicate that L1 dsRNA share a common origin in this fungus.

\section{Mechanisms of replant failure in ginseng cultivation.}

There were no significant differences in the infection rates of dsRNAs, level of virulence, and color intensity on the Bavendamm medium among the fungal populations collected from the two provinces. The frequency of strains containing L1 dsRNA, however, was highly affected by the field history. The infection rate of L1 dsRNA was significantly higher among strains collected from replanted fields than among strains from the first cropping fields in both geographic regions. This suggests that the prolongation of the cropping period of ginseng is associated with the increment of L1 dsRNA detection frequency. Because strains harboring L1 dsRNA were more virulent than those lacking L1 dsRNA, the increase in virulent strains containing L1 dsRNA might be responsible for replant failure in ginseng cultivation. It also has been suggested that replant failure in ginseng cultivation is a result of an increase in a highly pathogenic population of the fungus in the soil microbial community during replanting in the same field (Chung 1975). There are a number of potential mechanisms underlying the increase of strains carrying L1 dsRNA in replanted fields. First, rapid expansion of fungal populations containing L1 dsRNA through asexual reproduction and serial transmission may be possible. This is supported by the fact that L1 dsRNA was transmitted into progenies during conidiation at high frequency (about 99\%) in this fungus. Variable transmission rates of dsRNAs into conidia, ranging from 10 to $100 \%$, also were reported in C. parasitica strains (Enebak et al. 1994; Russin and Shain 1985). In this case, most $N$. radicicola strains would become the members of one, large clonal population. Furthermore, because strains containing L1 dsRNA have a higher fitness (higher levels of virulence and sporulation ability) than those lacking L1 dsRNA, propagation of these strains in the same niche may be more advantageous and rapid. Similar results also were ob- served in Fusarium oxysporum f. sp. niveum, the pathogen of Fusarium wilt of watermelon (Hopkins et al. 1992). As the culturing periods of host plants were prolonged, the population structure of the fungus shifted to more virulent forms. Reduction or disappearance of the strains lacking L1 dsRNA cannot be ruled out, and lateral transmission of L1 dsRNA by hyphal fusion also could be responsible for the change in population structure. Because of the homothallic nature of $N$. radicicola (Booth 1966), hyphal fusion may be a potential means for spreading L1 dsRNA. The above two speculations are supported by the fact that L1 dsRNA of Cy9201 hybridized to all 6.0-kbp dsRNAs detected in strains collected from difference sources, indicating that the 6.0-kbp dsRNAs in this fungus have the same, common origin.

\section{L1 dsRNA is responsible for the up regulation of fungal virulence.}

Elimination of L2, M, and S dsRNAs did not cause any phenotypic alterations in strains carrying these molecules. In contrast, elimination of L1 dsRNA resulted in the loss of virulence and virulence-related traits, including sporulation, pigmentation, and laccase activity. This was somewhat surprising considering the previous results showing hypovirulence caused by dsRNAs in other fungi (Boland 1992; Brasier

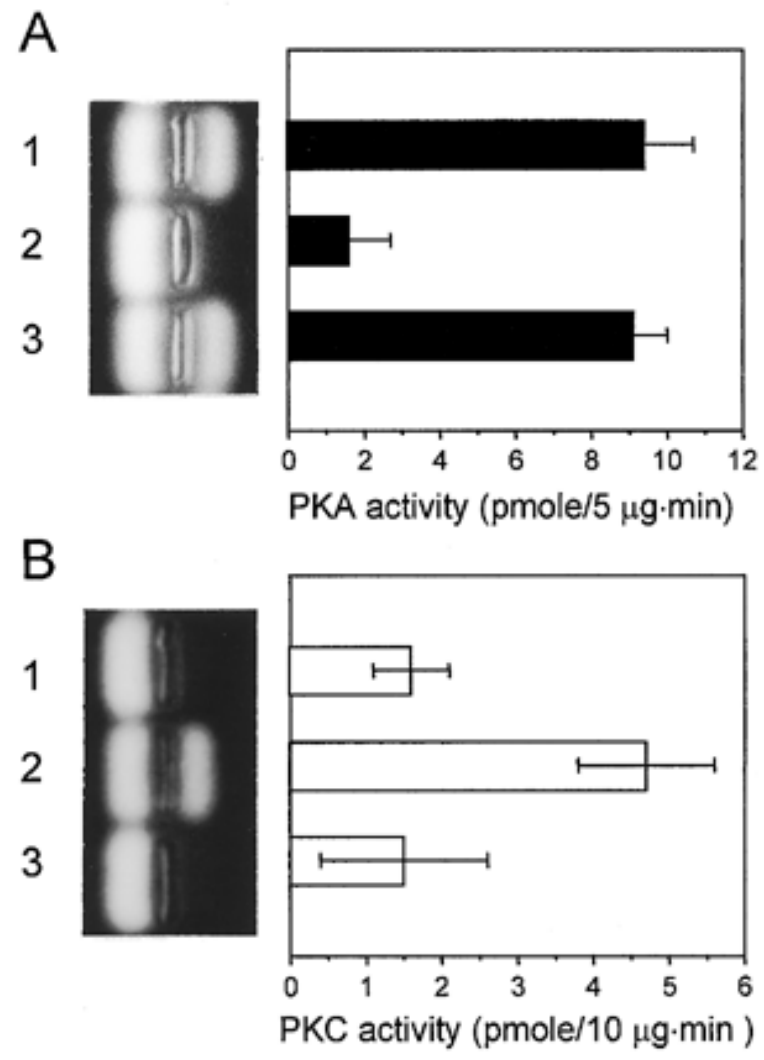

Fig. 6. Protein kinase activities in Nectria radicicola. Kinase activities were measured by gel electrophoresis and quantified with phosphorylated A1 or C1 peptides through spectrophotometry at $570 \mathrm{~nm}$. Activity is expressed in pmoles of phosphate transferred to a substrate per min per $5 \mu \mathrm{g}$ (cAMP-dependent protein kinases; PKA) and $10 \mu \mathrm{g}\left(\mathrm{Ca}^{2+}\right.$-dependent protein kinases; PKC) of total protein. A, Comparison of PKA activities. Lane 1, Cy9201; lane 2, NcCy9201; lane 3, T-1(3). B, Comparison of PKC activities. Lane 1, Cy9201; lane 2, NcCy9201; lane 3, T-1(3). 
1983; Castanho and Butler 1978; Choi and Nuss 1992b; Hammar et al. 1989; Zhou and Boland 1997). This effect also was suggested by the comparison of fungal strains with and without L1 dsRNA in the beginning of the experiments.

Although much effort has been made to eliminate specific dsRNAs from several fungi, there has been no report, to our knowledge, on the reintroduction of the same dsRNA into the cured strain. The reintroduction of the same dsRNA into the cured strain will satisfy Koch's postulates to prove the function of specific dsRNAs in fungal hosts. Transfection with a complementary DNA or single-stranded RNA copy of specific dsRNA into fungal hosts is another option to demonstrate the effect of dsRNA in fungal hosts by a cause-and-effect relationship (Choi and Nuss 1992a). In this study, we showed that reintroduction of L1 dsRNA (from Cy9201) into the dsRNAfree strain ( $\mathrm{NcCy} 9201$ marked with $H P H$ ) completely restored virulence and virulence-related traits such as sporulation ability, pigmentation, and laccase activity altered by elimination of L1 dsRNA in $N$. radicicola. This demonstrates that L1 dsRNA is responsible for the up regulation of fungal virulence, at least in strain Cy9201. Our study employed a single strain for elimination and reintroduction of the same L1 dsRNA and used a tagged strain to clearly differentiate donor and recipient strains. The strategy used in our study could serve as a model for future evaluation of specific dsRNAs in other fungi.

\section{L1 dsRNA perturbs signal-transduction pathways.}

Elimination and reintroduction of L1 dsRNA in this fungus affected a range of persistent phenotypes such as virulence, sporulation ability, pigmentation, and laccase activity. The pleiotropic nature of the phenotypic changes suggests a regulatory role of L1 dsRNA in fungal gene expression. L1 dsRNA may alter the components of signal-transduction pathways in the fungal host. As an initial attempt to characterize the mechanisms underlying these phenotype changes, we studied the effect of L1 dsRNA on two well-known signaling pathways; cAMP- and $\mathrm{Ca}^{2+}$-dependent pathways. Two strains harboring L1 dsRNA (Cy9201 and T-1[3]) had a sixfold increase of cAMP-dependent protein kinase (PKA) activity compared with that of the L1 dsRNA-cured strain (NcCy9201). PKA is the primary target of cAMP, an important second messenger in a wide range of organisms, and is activated by binding cAMP to the regulatory subunit of the enzyme (Gerisch 1987). Higher activity of PKA is indicative of a higher concentration of cAMP in the cells. Chen et al. (1996) reported that viral dsRNA infection elevated cAMP levels three- to fourfold in $C$. parasitica. Furthermore, cosuppression of $C P G-1$, a $\mathrm{G}$ protein alpha subunit gene, resulted in hypovirulence and elevated cAMP levels four- to fivefold (Choi et al. 1995). In spite of opposite effects on virulence, dsRNA infection increased the level of cAMP concentration in $C$. parasitica and $N$. radicicola. These data suggest that similar mechanism(s) exist to modulate the cAMP-dependent signaling pathway by dsRNA in both fungi. Although the precise mechanisms remain unknown, dsRNAs may modulate fungal gene expression by elevating levels of cAMP and subsequently activating PKA.

$\mathrm{Ca}^{2+}$ also is widely used as a second signaling messenger and regulates many different intracellular processes in a wide range of organisms (Clapman 1995). To dissect the possible involvement of calcium-dependent signaling pathways, we measured $\mathrm{Ca}^{2+}$-dependent protein kinase (PKC) activity. In $N$. radicicola, L1 dsRNA down regulated PKC activity. Surprisingly, a similar observation has been made in $C$. parasitica (Larson et al. 1992), where it was found that viral dsRNA interferes with signal transduction by the inositol triphosphate $\left(\mathrm{IP}_{3}\right)$-calcium dependent pathway in hypovirulent strains and depresses lac-1 transcription. Perturbation of $\mathrm{Ca}^{2+}$-dependent signaling system by viruses also has been reported in mammalian systems such as the influenza A virus (Hartshorn et al. 1992), human immunodeficiency virus (Fonti et al. 1999), and feline leukemia virus (Ehring et al. 2000). It is unclear, however, how L1 dsRNA participates in the signaling pathways to down regulate PKC activity in this fungus at the moment. It is interesting that though dsRNAs in both fungi regulate signaltransduction pathways in a similar manner, the phenotypes caused by dsRNAs are completely different. In $C$. parasitica, dsRNA depressed lac- 1 expression, but a higher level of laccase activity was observed in $N$. radicicola, which indicates that different mechanisms exist to regulate the same fungal genes in different organisms. L1 dsRNA oppositely regulates two important signal-transduction pathways in this fungus. Similarities in the perturbation of signal-transduction pathways by dsRNAs in $N$. radicicola and $C$. parasitica could provide a solid framework on the regulation of fungal virulence by dsRNA. Furthermore, understanding the interrelationship between cAMP- and $\mathrm{Ca}^{2+}$-dependent signaling pathways in fungi could provide more insight into the expression of fungal virulence.

\section{RNA-dependent RNA polymerase gene in L1 dsRNA.}

Alignment of the conserved regions of the RDRP gene in L1 dsRNA with those of other fungal viruses and single- and double-stranded plant viruses revealed that the RDRP genes of L1 dsRNA and FusoVM1 of $F$. solani f. sp. robiniae were grouped into three plant cryptic viruses that have dsRNAs as their genomes. The RDRP genes of other fungal viruses, including hypovirulence-associated dsRNA of $C$. parasitica, showed a closer phylogenetic relationship with those of single-stranded plant potyvirus, in accordance with a previous report (Koonin et al. 1991). Bruenn (1991) suggested that dsRNA viruses may constitute a monophyletic group in RDRP, although our data strongly suggest that RDRPs of dsRNA viruses represent polyphyletic groups. Sequencing of the entire L1 dsRNA and comparison of its genetic organization could bring more insight into its evolutionary relationship to other fungal viruses.

\section{MATERIALS AND METHODS}

\section{Fungal strains and culture conditions.}

$N$. radicicola strains were isolated from diseased ginseng tissues showing typical black root rot symptoms. After a single macroconidium isolation, identification of the fungus was carried out on the basis of mycological characteristics described by Booth (1966). Mycelia were grown in $250 \mathrm{ml}$ of Czapek Dox broth at $20^{\circ} \mathrm{C}$ with shaking at $120 \mathrm{rpm}$. After 2 weeks of incubation, mycelia were collected on two-layered cheesecloth via vacuum filtration, followed by washing twice with distilled water. Excessive moisture was removed by blotting the mycelia with filter paper and paper towels. The 
mycelia were then frozen at $-70^{\circ} \mathrm{C}$, lyophilized, and stored at $-70^{\circ} \mathrm{C}$. The lyophilized mycelia were used for dsRNA and genomic DNA extraction.

\section{DsRNA and genomic DNA extraction.}

DsRNA extraction, agarose gel electrophoresis, and confirmation of the dsRNA nature were carried out as described previously (Kim et al. 1996). Genomic DNA was isolated as described by Mitchell and Dean (1995). Northern analysis was performed as described by Lakshman and Tavantzis (1994).

\section{Elimination of dsRNA.}

Mycelial plugs of strains Cy9201 from Suwon (Korea), JP3-2-2 from Jeungpyung (Korea), SW3-5-3 from Suwon, and TSW3-4-1 from Suwon were transferred to potato dextrose agar (PDA) amended with 10 or $20 \mathrm{ppm}$ of cycloheximide or emetine, respectively (Sigma, St. Louis, MO, U.S.A). After a 2-week incubation at $20^{\circ} \mathrm{C}$ in the dark, agar plugs from colony margins were transferred to fresh PDA and grown in Czapek Dox broth, followed by dsRNA extraction analyses. For strain Cy9201, conidia were inoculated in $10 \mathrm{ml}$ of $5 \% \mathrm{~V} 8$ juice broth and incubated at $20^{\circ} \mathrm{C}$ with shaking at $120 \mathrm{rpm}$ for 8 days. After spreading the conidia on the Czapek Dox agar, individual colonies were evaluated for their morphology, pigmentation, and the presence of dsRNA.

\section{Pathogenicity assays.}

Virulence of all $N$. radicicola strains was evaluated at $20^{\circ} \mathrm{C}$ by inoculating surface-sterilized 2-year-old ginseng roots that were wounded slightly with a sterilized scalpel with $10 \mu \mathrm{L}$ of conidial suspensions $\left(1 \times 10^{6}\right.$ conidia per $\left.\mathrm{ml}\right)$. Inoculated ginseng roots were incubated in plastic boxes to maintain high relative humidity. After 10 days of incubation, disease severity was estimated with a scale of 0 to 2 , where $0=$ no disease; $1=$ root rot symptoms exhibiting a faint brown and symptom diameters less than $5 \mathrm{~mm}$, and $2=$ severe root rots exhibiting a deep brown and symptom diameters more than $5 \mathrm{~mm}$. All infection assays were conducted with three replications and repeated at least twice. Comparison of virulence among Cy9201, NcCy9201, and T-1(3) also was conducted with the soil-infestation method, as described by Owen (1956). The autoclaved soils ( sand:loam $=1: 1$, vol/vol) were mixed with rye grains $(0.1 \mathrm{~g}$ per $\mathrm{kg}$ of soil) infested with tester fungal strains. Two-year-old ginseng seedlings were planted in pots $($ diameter $\times$ height $=35 \times 25 \mathrm{~cm})$ and grown at $25 \pm 4^{\circ} \mathrm{C}$ under continuous shade. Four ginseng seedlings were planted in each pot and used for each strain. Nectria root rot was assessed by visual inspection of the plants for wilt symptoms, and its disease severity was verified as the root rot area $\left(\mathrm{mm}^{2}\right)$ at 2 weeks after planting.

\section{Sporulation, Bavendamm test, and mycelial growth.}

Conidia of individual strains grown on Czapek Dox agar for 10 days under a $16 \mathrm{~h}$ photoperiod were harvested with sterilized distilled water. One thousand conidia in $100 \mu \mathrm{l}$ were inoculated in $5 \mathrm{ml}$ of $5 \% \mathrm{~V} 8$ juice broth in a test tube (diameter $\times$ length $=17 \times 170 \mathrm{~mm}$ ). The sporulation level was estimated at 8 days after incubation at $20^{\circ} \mathrm{C}$ and $120 \mathrm{rpm}$ with $16 \mathrm{~h}$ photoperiods. A Bavendamm test was performed as described by Rigling et al (1989). Coloring of the medium was estimated at 10 days after incubation at $20^{\circ} \mathrm{C}$ in the dark with three replications. Mycelial growth of each strain was assayed on the Czapek Dox agar at 7 days after incubation at $20^{\circ} \mathrm{C}$ with three replications (Kousik et al. 1994).

\section{Laccase activity assay.}

Fungal strains Cy9201, NcCy9201, and T-1(3) were grown on Czapek Dox agar overlaid with a sterilized cellophane film at $20^{\circ} \mathrm{C}$ in the dark for 8 days. The mycelia on the cellophane film were recovered aseptically and homogenized. The resulting slurry ( $1 / 10$ of the medium volume) was inoculated in Czapek Dox broth and incubated at $20^{\circ} \mathrm{C}$ with shaking at 120 $\mathrm{rpm}$. Proteins from mycelia and culture filtrates were used for measuring intracellular and extracellular laccase activities, respectively. Laccase activity was determined with 2,6dimethoxyphenol as the substrate. One unit was defined as an increase of absorbance of 1.0 per min at $468 \mathrm{~nm}$ and $25^{\circ} \mathrm{C}$. For intracellular and extracellular laccase activity determinations, $100 \mu \mathrm{g}$ of protein from mycelia and $10 \mu \mathrm{g}$ protein from culture filtrates were used, respectively. Extraction of mycelial protein and preparation of fluid protein was performed as described by Rigling and Van Alfen (1991). Protein concentration was determined as described by Bradford (1976).

\section{Transformation.}

Mycelia of $N$. radicicola $\mathrm{NcCy} 9201$ were recovered from the cellophane film overlaid on the FMM (Puhalla 1985). The homogenized mycelia were inoculated in $100 \mathrm{ml}$ of FMM broth. After 2-day incubation at $25^{\circ} \mathrm{C}$, mycelia were harvested and washed twice with an equal volume of OM buffer (1.4 M $\mathrm{MgSO}_{4} 7 \mathrm{H}_{2} \mathrm{O}$ in $10 \mathrm{mM}$ sodium phosphate buffer, $\mathrm{pH}$ 6.8) by centrifugation at 5,000 rpm for $10 \mathrm{~min}$. The mycelial pellet was resuspended in $20 \mathrm{ml}$ of OM buffer containing $10 \mathrm{mg}$ of Novozym 234 per ml (Novo Nordisk, Danbury, CT, U.S.A.) and $3 \mathrm{mg}$ of driselase (Sigma) per $\mathrm{ml}(5 \mathrm{ml}$ per $100 \mathrm{mg}$ of mycelia) and incubated for $3 \mathrm{~h}$ at $25^{\circ} \mathrm{C}$ with gentle shaking. Undigested mycelia and debris were removed by filtration through four layers of cheesecloth, followed by a sintered glass filter ( $20 \mu \mathrm{m}$ pore size $)$. The sphaeroplasts were washed twice by centrifugation for $5 \mathrm{~min}$ at $5,000 \mathrm{rpm}$ with an equal volume of OM buffer and then resuspended in STC (1 M sorbitol; $50 \mathrm{mM}$ Tris $\mathrm{HCl}, \mathrm{pH} 8.0$; and $10 \mathrm{mM} \mathrm{CaCl}_{2}$ ). Twenty $\mu \mathrm{g}$ of pDH25 (Cullen et al. 1987) in $20 \mu \mathrm{L}$ of Tris-EDTA (pH 8.0) was added to the $5 \times 10^{6}$ sphaeroplasts. An equal volume of $30 \%$ polyethylene glycol (PEG) 3,350 in $10 \mathrm{mM} \mathrm{CaCl}_{2}$ was added to the mixture of DNA and sphaeroplasts. The suspension was incubated for $30 \mathrm{~min}$ at $25^{\circ} \mathrm{C}$, followed by centrifugation for $5 \mathrm{~min}$ to remove PEG. The pelleted sphaeroplasts were resuspended in $500 \mu \mathrm{l} \mathrm{STC}$, and $100 \mu \mathrm{l}$ of sphaeroplasts was plated on each plate of FMM containing $1.4 \mathrm{M} \mathrm{MgSO}_{4} \times$ $7 \mathrm{H}_{2} \mathrm{O}$. After incubation for 2 days at $25^{\circ} \mathrm{C}$, each FMM plate was overlaid with $5 \mathrm{ml}$ of FMM $(0.8 \%$ agar) containing $50 \mu \mathrm{g}$ of hygromycin B per $\mathrm{ml}$ and then incubated in the dark for 7 days at $25^{\circ} \mathrm{C}$. Hygromycin-resistant colonies were transferred again onto FMM amended with $50 \mu \mathrm{g}$ of hygromycin B per $\mathrm{ml}$. Transformation was confirmed by Southern analysis, as described by Sambrook et al. (1989).

\section{Transmission of $6.0 \mathrm{kbp}$ dsRNA.}

To transfer 6.0-kbp (L1) dsRNA from strain Cy9201 to T-1, a hygromycin B-resistant transformant of $\mathrm{NcCy} 9201$, mycelial plugs of T-1 were placed around a 7-day-old colony of 
Cy9201 on Czapek Dox agar and allowed to grow for 4 days after mycelial contact. Mycelial plugs from the margin of the recipient colony $\mathrm{T}-1$ were transferred onto Bavendamm medium in 24-well tissue-culture plates and FMM amended with $50 \mu \mathrm{g}$ of hygromycin B per ml. Strains exhibiting hygromycin resistance as well as color reaction on the Bavendamm medium were selected as candidates for L1 dsRNA-transmission. Each colony selected was subjected to dsRNA extraction, pathogenicity tests, and measurement of laccase activities. Transmission was confirmed by Northern analysis with pL172, a cDNA fragment synthesized from the L1 dsRNA, as probe. Northern analysis was performed as described by Lakshman and Tavantzis (1994).

\section{Construction of cDNA library and cDNA sequencing.}

Five $\mu \mathrm{g}$ of $6.0-\mathrm{kbp}$ dsRNA in $5 \mu \mathrm{l}$ of diethyl pyrocarbonate (DEPC)-treated distilled water was mixed with $1.5 \mu \mathrm{g}$ of random nonamer, which made up to $15 \mu \mathrm{l}$ of dsRNA with DEPCtreated distilled water. dsRNA was denatured by boiling at approximately 95 to $100^{\circ} \mathrm{C}$ for $5 \mathrm{~min}$. After the sample was quenched in liquid $\mathrm{N}_{2}$, the temperature was increased slowly up to $42^{\circ} \mathrm{C}$. The first- and second-strand syntheses and end filling of cDNA fragments were carried out as described by the manufacturer's recommendations (Takara, Ohtsu, Japan). The resulting cDNA was purified by filtration through a Sephadex G-50 column. The synthesized cDNA was blunt ligated into SmaI-digested pBluescript $\mathrm{SK}(+)$ and transformed into competent cells of Escherichia coli DH10B by electroporation. The cDNA inserts were confirmed by digesting purified plasmids with EcoRI and XhoI. Sequencing of the 6.0kbp dsRNA-specific cDNA clones was carried out with the DyeTerminator thermocycle sequencing kit (Applied Biosystems, Warrington, U.K.) with an ABI 377 automatic DNA sequencer (Applied Biosystems).

\section{Protein kinase assay.}

Mycelia of Cy9201, NcCy9201, and T-1(3) grown in 100 $\mathrm{ml}$ of FMM at $20^{\circ} \mathrm{C}$ with shaking at $120 \mathrm{rpm}$ for 5 days were harvested on four-layered cheesecloth. Harvested mycelia were macerated in liquid $\mathrm{N}_{2}$ and resuspended in $100 \mu \mathrm{l}$ of protein extraction buffer $(50 \mathrm{mM}$ potassium phosphate buffer, $\mathrm{pH} 7.6 ; 10 \mathrm{mM} \beta$-mercaptoethanol; $4 \mathrm{mM}$ ethylene glycolbis[ $\beta$-aminoethyl ether]- $N, N, N^{\prime}, N^{\prime}$-tetraacetic acid; and 0.5 $\mathrm{mM}$ phenylmethylsulfonyl fluoride). The mixture was centrifuged at $13,000 \mathrm{rpm}$ for $40 \mathrm{~min}$ at $4^{\circ} \mathrm{C}$. Concentration of protein in the supernatant was quantified with the methods described by Bradford (1976). cAMP-dependent protein kinase and protein kinase $\mathrm{C}$ activities were analyzed with a nonradioactive assay system following the manufacturer's instruction (Promega, Madison, WI, U.S.A.). One unit of kinase is defined as the number of pmoles of phosphate transferred per minute to a substrate.

\section{ACKNOWLEDGMENTS}

This work was supported by the Brain Korea 21 project.

\section{LITERATURE CITED}

Altschul, S. F., Gish, W., Miller, W., Myers, E. W., and Lipman, D. J. 1988. Gapped BLAST and PSI-BLAST: A new generation of protein database search programs. J. Mol. Biol. 215:403-410.

Anagnostakis, S. L., and Day, P. R. 1979. Hypovirulence conversion in Endothia parasitica. Phytopathology 69:1226-1229.

Bharathan, N., and Tavantzis, S. M. 1990. Genetic diversity of doublestranded RNA from Rhizoctonia solani. Phytopathology 80:631-635.

Bharathan, N., and Tavantzis, S. M. 1991. Assessment of genetic relatedness among double-stranded RNAs from isolates of Rhizoctonia solani from diverse geographic origins. Phytopathology 81:411-415.

Boland, G. J. 1992. Hypovirulence and double-stranded RNA in Sclerotinia sclerotiorum. Can. J. Plant Pathol. 14:10-17.

Booth, G. 1966. The genus Cylindrocarpon. Commonw. Mycol. Pap. 104:1-56.

Bottacin, A. M., Lévesque, C. A., and Punja, Z. K. 1994. Characterization of dsRNA in Chalara elegans and effects on growth and virulence. Phytopathology 84:303-312.

Bradford, M. M. 1976. A rapid and sensitive method for the quantitation of microgram quantities of protein utilizing the principle of proteindye binding. Anal. Biochem. 72:248-254.

Brasier, C. M. 1983. A cytoplasmically transmitted disease of Ceratocystis ulmi. Nature 305:220-222.

Bruenn, J. A. 1991. Relationships among the positive strand and doublestrand RNA viruses as viewed through their RNA-dependent RNA polymerases. Nucleic Acid Res. 19:217-226.

Buck, K. W. 1986. Fungal virology: An overview. Pages 1-84 in: Fungal Virology. K. W. Buck, ed. CRC Press, Boca Raton, FL, U.S.A.

Castanho, B., and Butler, E. E. 1978. Rhizoctonia decline: A degenerative disease of Rhizoctonia solani. Phytopathology 68:1505-1510.

Chen, B., Choi, G. H., and Nuss, D. L. 1994. Attenuation of fungal virulence by synthetic infectious hypovirus transcripts. Science 264:1762-1764.

Chen, B., Gao, S., Choi, G. H., and Nuss, D. L. 1996. Extensive alteration of fungal gene transcript accumulation and elevation of Gprotein-regulated cAMP levels by a virulence-attenuating hypovirus. Proc. Natl. Acad. Sci. USA 93:7996-8000.

Choi, G. H., and Nuss, D. L. 1992a. Hypovirulence of chestnut blight fungus conferred by an infectious viral cDNA. Science 257:800-803.

Choi, G. H., and Nuss, D. L. 1992b. A viral gene confers hypovirulenceassociated traits to the chestnut blight fungus. EMBO J. 11:473-477.

Choi, G. H., Chen, B., and Nuss, D. L. 1995. Virus-mediated or transgenic suppression of a G-protein a subunit and attenuation of fungal virulence. Proc. Natl. Acad. Sci. USA 92:305-309.

Chun, S.-J., and Lee, Y.-H. 1997. Inheritance of dsRNAs in the rice blast fungus, Magnaporthe grisea. FEMS Microbiol. Lett. 148:159-162.

Chung, H.-S. 1975. Studies on Cylindrocarpon destructans (Zins.) Scholten causing root rot of ginseng. Rep. Tottori Mycol. Inst. 12:127-138.

Chung, H.-S., and Kim, C.-H. 1978. Biological control of ginseng root rots with soil amendments. Pages 67-74 in: Proceedings of the 2nd International Ginseng Symposium, Korea Ginseng Research Institute, Seoul, Korea.

Chung, P.-H., Bedker, P. J., and Hillman, B. I. 1994. Diversity of Cryphonectria parasitica hypovirulence-associated double-stranded RNAs within a chestnut population in New Jersey. Phytopathology 84:984-990.

Clapman, D. E. 1995. Calcium signaling. Cell 80:259-268.

Cullen, D., Leong, S. A., Wilson, L. J., and Henner, D. J. 1987. Transformation of Aspergillus nidulans with the hygromycin resistance gene, $h p h$. Gene 57:21-26.

Ehring, G. R., Kerschbaum, H. H., Fanger, C. M., Eder, C., Rauer, H. and Caharan, M. D. 2000. Vandate induces calcium signaling, $\mathrm{Ca}^{2+}$ release-activated $\mathrm{Ca}^{2+}$ channel activation, and gene expression in $\mathrm{T}$ lymphocytes and RBL-2H3 mutant cells via thiol oxidation. J. Immunol. 164:679-687.

Elias, K. S., and Cotty, P. J. 1996. Incidence and stability of infection by double-stranded RNA genetic elements in Aspergillus section flavi and effects on aflatoxigenicity. Can. J. Bot. 74:716-725.

Enebak, S. A., MacDonald, W. L., and Hillman, B. I. 1994. Effect of dsRNA associated with isolates of Cryphonectria parasitica from the central Appalachians and their relatedness to other dsRNAs from North America and Europe. Phytopathology 84:528-534.

Fonti, M., Cartier, L., Piguet, V., Lew, D. P., Trono, D., and Krause, K. H. 1999. The HIV Nef protein alters $\mathrm{Ca}^{2+}$ signaling in myeolomonocytic cells through SH3-mediated protein-protein interactions. J. Biol. Chem. 274:34765-34772. 
Fulbright, D. W. 1984. Effect of eliminating dsRNA in hypovirulent Endothia parasitica. Phytopathology 74:722-724.

Gerisch, G. 1987. Cyclic AMP and other signals controlling cell development and differentiation in Dictyostelium. Annu. Rev. Biochem. $56: 853-879$

Hammar, S., Fulbright, D. W., and Adams, G. C. 1989. Association of double-stranded RNA with low virulence in an isolate of Leucostoma persoonii. Phytopathology 79:568-572.

Hartshorn, K. L., Daigneault, D. E., White, M. R., Tuvin, M., Tauber, J. L., and Tauber, A. I. 1992. Comparison of influenza A virus and formyl-methionyl-leucyl-phenylalanine activation of the human neutrophil. Blood 79:1049-1057.

Hollings, M. 1982. Mycoviruses and plant pathology. Plant Dis. 66:1106-1112.

Hong, Y., Dover, S. L., Cole, T. E., Brasier, C. M., and Buck, K. W. 1999. Multiple mitochondrial viruses in an isolate of the Dutch elm disease fungus Ophiostoma novo-ulmi. Virology 258:118-127.

Hopkins, D. L., Lobinske, R. J., and Larkin, R. P. 1992. Selection for Fusarium oxysporum $\mathrm{f}$. sp. niveum race 2 in monocultures of watermelon cultivars resistant to Fusarium wilt. Phytopathology 82:290293.

Jian, J., Lakshman, D. K., and Tavantzis, S. M. 1997. Association of distinct double-stranded RNAs with enhanced or diminished virulence in Rhizoctonia solani infecting potato. Mol. Plant-Microbe Interact. 10:1002-1009.

Kazmierczak, P., Pfeiffer, P., Zhang, L., and Van Alfen, N. K. 1996. Transcriptional repression of specific host genes by the mycovirus Cryphonectria Hypovirus 1. J. Virol. 70:1137-1142.

Kim, S.-O., Chung, H.-S., and Lee, Y.-H. 1996. Double-stranded RNAs in Korean isolates of Rhizoctonia solani AG4. FEMS Microbiol. Lett. 141:203-206.

Koonin, E. V., Choi, G. H., Nuss, D. L., Shapira, R., and Carrington, J. C. 1991. Evidence for common ancestry of a chestnut blight hypovirulence-associated double-stranded RNA and a group of positive strand RNA plant viruses. Proc. Natl. Acad. Sci. USA 88:1064710651.

Kousik, C. S., Snow, J. P., and Valverde, R. A. 1994. Comparison of double-stranded RNA components and virulence among isolates of Rhizoctonia solani AG-1IA and AG-1IB. Phytopathology 84:44-49.

Kwon, W.-S., Chung, C.-M., Kim, O.-T., Lee, M.-G., and Choi, K.-T. 1998. Breeding process and characteristics of KG101, a superior line of Panax ginseng C. A. Meyer. Korean J. Ginseng Sci. 22:11-17.

Lakshman, D. K., and Tavantzis, S. M. 1994. Spontaneous appearance of genetically distinct double-stranded RNA elements in Rhizoctonia solani. Phytopathology 84:633-639.

Larson, T. G., Choi, G. H., and Nuss, D. L. 1992. Regulatory pathways governing modulation of fungal gene expression by a virulenceattenuating mycovirus. EMBO J. 11:4539-4548.

Lee, S.-C., and Lee, Y.-H. 1998. Calcium/calmodulin-dependent signaling for appressorium formation in the plant pathogenic fungus Magnaporthe grisea. Mol. Cell 8:698-704.

Lee, Y.-H., and Dean, R. A. 1993. cAMP regulates infection structure formation in the plant pathogenic fungus Magnaporthe grisea. Plant Cell 5:693-700.

Magliani, W., Conti, S., Gerloni, M., Bertolotti, D., and Polonelli, L. 1997. Yeast killer systems. Clin. Microbiol. Rev. 10:369-400.

Matuo, T., and Miyazawa, Y. 1969. On Cylindrocarpon panacis sp. nov. causing root rot of ginseng. Trans. Mycol. Soc. Jpn. 9:109-112.

McFadden, J. J. P., Buck, K. W., and Rawlinson, C. J. 1983. Infrequent transmission of double-stranded RNA virus particles but absence of DNA proviruses in single ascospore cultures of Gaeumannomyces graminis. J. Gen. Virol. 64:927-937.

Mitchell, T. K., and Dean, R. A. 1995. The cAMP-dependent protein kinase catalytic subunit is required for appressorium formation and pathogenicity by the rice blast fungus Magnaporthe grisea. Plant Cell 7:1869-1878

Miyazawa, Y. 1966. Studies on control ginseng root rot. Nogyo Oyobi Engei 45:101-105.

Newhouse, J. R., Hoch, H. C., and MacDonald, W. L. 1983. The ultra- structure of Endothia parasitica. Comparison of a virulent with a hypovirulent isolate. Can. J. Bot. 61:389-399.

Nogawa, M., Kageyama, T., Nakatani, A., Taguchi, G., Shimosaka, M., and Okazaki, M. 1996. Cloning and characterization of mycovirus double-stranded RNA from the plant pathogenic fungus, Fusarium solani f. sp. robiniae. Biosci. Biotech. Biochem. 60:784-788.

Nuss, D. L. 1996. Using hypoviruses to probe and perturb signal transduction processes underlying fungal pathogenesis. Plant Cell 8:18451853.

Owen, J. H. 1956. Cucumber wilt, caused by Fusarium oxysporum f. cucumerinum $\mathrm{n}$. f. Phytopathology 46:153-157.

Page, R. D. M. 1996. TreeView: An application to display phylogenetic trees on personal computers. Comput. Appl. Biosci. 12:357-358.

Poch, O., Sauvaget, I., Delarue, M., and Tordo, N. 1989. Identification of four conserved motifs among the RNA-dependent polymerase encoding elements. EMBO J. 8:3867-3874.

Puhalla, J. E. 1985. Classification of strains of Fusarium oxysporum on the basis of vegetative compatibility. Can. J. Bot. 62:540-545.

Reeleder, R. D., and Brammall, R. A. 1994. Pathogenicity of Pythium species, Cylindrocarpon destructans, and Rhizoctonia solani to ginseng seedlings in Ontario. Can. J. Plant Pathol. 16:311-316.

Revill, P. A., Davidson, A. D., and Wright, P. J. 1994. The nucleotide sequence and genome organization of mushroom bacilliform virus: A single-stranded RNA virus of Agaricus bisporus (Lange) Imbach. Virology 202:904-911.

Rigling, D., and Van Alfen, N. K. 1991. Regulation of laccase biosynthesis in the plant pathogenic fungus Cryphonectria parasitica by double-stranded RNA. J. Bacteriol. 173:8000-8003.

Rigling, D., and Van Alfen, N. K. 1993. Extra- and intracellular laccase of the chestnut blight fungus, Cryphonectria parasitica. Appl. Environ. Microbiol. 59:3634-3639.

Rigling, D., Heiniger, U., and Hohl, H. R. 1989. Reduction of laccase activity in dsRNA-containing hypovirulent strains of Cryphonectria (Endothia) parasitica. Phytopathology 79:219-223.

Rogers, H. J., Buck, K. W., and Brasier, C. M. 1986. Transmission ofdouble-stranded RNA and a disease factor in Ophiostoma ulmi. Plant Pathol. 35:277-287.

Russin, J. S., and Shain, L. 1985. Disseminative fitness of Endothia parasitica containing different agents for cytoplasmic hypovirulence. Can. J. Bot. 65:54-57.

Sambrook, J., Fritsch, E. F., and Maniatis, T. 1989. Molecular Cloning: A Laboratory Manual, 2nd ed., Cold Spring Harbor Laboratory, Cold Spring Harbor, NY, U.S.A.

Strauss, E. E., Lakshman, D. K., and Tavantzis, S. M. 2000. Molecular characterization of the genome of a partivirus from the basidiomycete Rhizoctonia solani. J. Gen. Virol. 81:549-555.

Thompson, J. D., Higgins, D. G., and Gibson, T. J. 1994. CLUSTAL W: Improving the sensitivity of progressive multiple sequence alignment through sequence weighting, position-specific gap penalties and weight matrix choice. Nucleic Acid Res. 22:4673-4680.

Tooley, P. W., Hewings, A. D., and Falkenstein, K. F. 1989. Detection of double-stranded RNA in Phytophthora infestans. Phytopathology 79:470-474.

Varga, J., Kevel, F., Vagvolgyi, C., Vriesema, A., and Croft, J. H. 1994. Double-stranded RNA mycoviruses in section Nigri of the Aspergillus genus. Can. J. Microbiol. 40:325-329.

Wang, P., and Nuss, D. L. 1995. Induction of a Cryphonectria parasitica cellobiohydrolase I gene is suppressed by hypovirus infection and regulated by a GTP-binding-protein-linked signaling pathway involved in fungal pathogenesis. Proc. Natl. Acad. Sci. USA 92:11529-11533.

Zhang, L., Churchill, A. C. L., Kazmierczak, P., Kim, D.-H., and Van Alfen, N. K. 1993. Hypovirulence-associated traits induced by a mycovirus of Cryphonectria parasitica are mimicked by targeted inactivation of a host gene. Mol. Cell Biol. 13:7782-7792.

Zhou, T., and Boland, G. J. 1997. Hypovirulence and double-stranded RNA in Sclerotinia homoeocarpa. Phytopathology 87:147-153.

Ziezold, A. M., Reeleder, R. D., Hall, R., and Proctor, J. T. A. 1998. Seedborne fungi and fungicide seed treatment to of ginseng. J. Ginseng Res. 22:229-236. 